\title{
La prescripción de la facultad para determinar infracciones administrativas
}

Dante Mendoza Antonioli

Abogado por la Pontificia Universidad Católica del Perú.

Magister en Ciencias de la Administración Pública por la Universidad Alemana de Ciencias Administrativas Speyer —-Deutsche Hochschule für

Verwaltungswissenshaften Speyer-. Profesor de Derecho Administrativo en la Universidad de Lima y en la

Universidad Jesuita Antonio Ruíz de Montoya.

SUMARI0:

I. Introducción.

II. La prescripción en el Derecho Administrativo Sancionador es una figura sustantiva.

III. Suspensión e interrupción del plazo de prescripción.

IV. La prescripción opera automáticamente.

V. La regla general del plazo de prescripción de la LPAG.

VI. En conclusión. 


\section{RESUMEN:}

El autor desarrolla cuatro problemas de interpretación de la regulación nacional respecto a la prescripción de la potestad sancionadora del Estado, presentando el desarrollo que cada una de ellas ha merecido en el tiempo de vigencia de la Ley № 27444, Ley del Procedimiento Administrativo General.

Palabras clave: Prescripción; Procedimiento sancionador; Caducidad; Suspensión del plazo; Interrupción del plazo.

\footnotetext{
ABSTRACT:

The author develops four problems of interpretation of the national regulation regarding the prescription of the sanctioning power of the State, presenting the development that each one of them has deserved in the time of validity of Law No. 27444, Law of General Administrative Procedure.

Keywords: Prescription; Penalty procedure; Expiration; Suspension of the term; Term interruption.
}

\section{INTRODUCCIÓN}

Ante la real necesidad de dotar a las instituciones del Derecho Administrativo de un contenido propio y acorde con su naturaleza, que permita desarrollar las relaciones entre la administración pública y los administrados en un marco no solo de certeza y predictibilidad, sino también de coherencia con los principios que esta relación reclama; la Ley del Procedimiento Administrativo General - Ley 27444, en adelante, "LPAG" - desde su promulgación, en el año 2001, ha merecido interpretaciones de diversa índole, que la han ido perfilando como una herramienta moderna que representa un Estado al servicio del ciudadano, y donde la regla es la de la interpretación en "pro del administrado".

Estas interpretaciones, pasaron de la doctrina al texto expreso de la ley a través de un proceso de diversas modificaciones legislativas operadas a lo largo de los 25 años de vigencia de la misma y que han configurado una norma mas robusta y predecible para la ciudadanía, con reglas cada vez más explícitas en su vocación de establecer una nueva relación entre la administración y los administrados.

Las disposiciones relativas a la potestad sancionadora del Estado y el procedimiento sancionador no son la excepción a este proceso de evolución normativa. A lo largo del tiempo se han ido precisando los conceptos y los alcances de la norma, siempre fortaleciendo una posición interpretativa en favor del ciudadano.

El paso del tiempo tiene consecuencias en el Derecho. Una de ellas es la prescripción. En el Derecho Administrativo sancionador la figura toma especial relevancia desde que la demora de la administración para determinar una infracción y establecer su consiguiente sanción, puede tener como consecuencia la imposibilidad de hacerlo y que la sensación de impunidad que se genera en la sociedad termine en sospecha de corrupción, afectando la estabilidad y gobernabilidad del país.

La prescripción es una garantía establecida en favor de los ciudadanos frente al actuar moroso de la Administración Pública. No es posible sostener la legitimidad de la actuación administrativa, incluso en el caso de infracciones evidentes por parte de los ciudadanos, si es que éstas no se procesan con celeridad y diligencia.

La importancia de esta figura y las consecuencias que se puedan derivar de su aplicación por parte de las entidades públicas, en cuatro temas concretos, se analizan en el presente artículo.

\section{LA PRESCRIPCIÓN EN EL DERECHO AD- MINISTRATIVO SANCIONADOR ES UNA FIGURA SUSTANTIVA}

La naturaleza jurídica de la prescripción de la potestad sancionadora de la Administración 
Pública es un tema que ha generado controversia por su errada asimilación al concepto y extensión del término en el Derecho Civil o en el Derecho Penal.

Sin embargo, se debe advertir que en el Derecho Administrativo nacional la prescripción es una figura sustantiva que determina la extinción de la competencia de la administración pública para poder perseguir una infracción a cualquier norma por parte de los administrados.

A diferencia de las figuras de prescripción y caducidad en el Derecho Civil, donde de manera muy general podemos afirmar que mientras que la primera extingue la acción -y por ello es considerada una figura procesal-, y la segunda extingue el derecho; en el Derecho Administrativo sancionador lo que existe es una figura diferente que tiene la virtualidad de extinguir en simultáneo la acción y el derecho.

A esta figura la denominamos prescripción de la potestad sancionadora del Estado y se deriva del deber de la Administración Pública de ejercer sus funciones con estricto apego al principio de legalidad y debido procedimiento, los mismos que le imponen la obligación de respetar los plazos establecidos legalmente y establecen una consecuencia en favor del administrado, quien tiene, como parte del Derecho a una buena Administración Pública, el que los plazos sean respetados y que el ejercicio de la potestad sancionadora no esté sujeto a los tiempos ni humores de los funcionarios de turno, sino a un plazo pre determinado, claro y razonable.

No existe la figura de la caducidad de un supuesto derecho de la Administración Pública para ejercer su potestad sancionadora. En el procedimiento administrativo sancionador la única figura sustantiva que existe es la prescripción de la facultad de la administración para determinar la infracción de alguna obligación legal por parte de los administrados.

La caducidad es un término reservado en la Ley 27444 —LPAG - para el plazo máximo que puede durar un procedimiento sancionador iniciado de oficio. Es una figura distinta, de carácter eminentemente procedimental y que atañe directamente a la duración máxima del procedimiento y deja intacta la posibilidad de volver a iniciarlo, en tanto la facultad de la administración para determinar la infracción no haya prescrito.

\section{SUSPENSIÓN E INTERRUPCIÓN DEL PLA- ZO DE PRESCRIPCIÓN}

Ambos conceptos son desarrollados extensamente desde el Derecho Civil. Sin embargo, en materia de Derecho Administrativo el alcance de estos términos merece una precisión.

Vale recordar que históricamente las normas del Derecho Civil y Procesal Civil fueron las aplicables cuando se trataba de problemas y relaciones de los ciudadanos con la administración pública y es recién a partir de 1967, con el Decreto Supremo № 006-67-SC, cuando tímidamente se establece un primer esfuerzo por generar normas comunes a los procedimientos administrativos, posición que se reafirma en 1991 con el Decreto Legislativo 757 y luego en 1992 con el Decreto Ley 26122. Sin embargo, es recién con la Ley 27444 que el Derecho Administrativo en nuestro país reclama con claridad y de manera explícita, legislativamente hablando, un conjunto de principios, garantías, conceptos y un procedimiento propio, que lo caracterice e independice totalmente como una disciplina propia y autónoma dentro de nuestro sistema jurídico.

En este contexto, el legislador trató de establecer conceptos propios que resulten adecuados a la naturaleza propia del Derecho Administrativo, pero no cuidó de generar en todos los casos nombres distintos de los utilizados en el Derecho Civil.

Por ello, en el caso concreto del plazo de prescripción, en donde la única consecuencia posible del inicio del procedimiento administrativo sancionador es que el plazo prescriptorio se paralice durante el tiempo que dure éste, vale decir la "suspensión" en términos civiles, el texto original de la LPAG utilizó — con una marcada influencia de la legislación española - el tér-

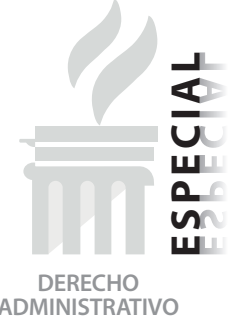

MINISTRATIVO 
mino "interrupción"1 y pese a que le adjudicó expresamente las mismas consecuencias que el Derecho Civil le atribuye a la suspensión, no fueron pocos los problemas de interpretación que se generaron. A muchos no les quedaba claro si el plazo prescriptorio se interrumpía o se suspendía con el inicio del procedimiento sancionador respectivo, más aún si consideramos que el Código Penal contempla también ambas figuras $^{2}$ con consecuencias similares a las previstas en la legislación civil.

El problema era real y las consecuencias importantes para el administrado. Recordemos que, siempre desde la perspectiva civilista, la interrupción del plazo genera que éste regrese a cero y que vuelva a correr desde el inicio. En tanto que, con la suspensión, el plazo solo se paraliza y la cuenta vuelve a reanudarse una vez que se supera aquello que originó la paralización.

Este problema se solucionó definitivamente con la modificación efectuada en el año 2008 por el Decreto Legislativo 1029 que reemplazó la palabra "interrupción" por la de "suspensión", eliminando así toda duda respecto al tratamiento que se debe dar al plazo de prescripción cuando se inicia un procedimiento administrativo sancionador.

Por ello es claro que hoy, en nuestra legislación, el plazo prescriptorio de la potestad sanciona- dora de la Administración Pública no se interrumpe sino solamente se suspende. La LPAG es muy clara al establecer un solo supuesto de suspensión: el inicio del procedimiento con la notificación de cargos correspondiente. No existe otra causal.

Cabe advertir que no obstante la propia ley reconoce la validez de las actuaciones preliminares, la realización de éstas bajo ninguna circunstancia suspende el plazo prescriptorio. Únicamente con la notificación de cargos y el inicio formal del procedimiento es que podemos evidenciar la suspensión.

Cuando se notifican los cargos el plazo se suspende por toda la duración del procedimiento, salvo que éste se paralice, por causa no imputable al administrado, por más de veinticinco días - en cuyo caso el cómputo del plazo se reanuda-; o, en el caso de caducidad por el que el procedimiento desaparece y se tiene por inexistente, generándose una ficción procesal, con el efecto de considerar que el procedimiento nunca se inició y por lo tanto el plazo de prescripción nunca se suspendió.

\section{LA PRESCRIPCIÓN OPERA AUTOMÁTICA- MENTE}

Otro tema de debate al interior de estas disposiciones es respecto a si es necesario oponer la

1. Artículo 233.2 de la Ley $N^{\circ} 27444$, en su versión original: "Artículo $233^{\circ}$ Prescripción

(...)

233.2 El plazo de prescripción solo se interrumpe con la iniciación del procedimiento sancionador, reanudándose el plazo si el expediente se mantuviera paralizado durante más de un mes por causa no imputable al administrado"

2. Artículos 83 y 84 del Código Penal aprobado por Decreto Legislativo № 635:

"Artículo 83.- Interrupción de la prescripción de la acción penal

La prescripción de la acción se interrumpe por las actuaciones del Ministerio Público o de las autoridades judiciales, quedando sin efecto el tiempo transcurrido.

Después de la interrupción comienza a correr un nuevo plazo de prescripción, a partir del día siguiente de la última diligencia.

Se interrumpe igualmente la prescripción de la acción por la comisión de un nuevo delito doloso. Sin embargo, la acción penal prescribe, en todo caso, cuando el tiempo transcurrido sobrepasa en una mitad al plazo ordinario de prescripción.

Artículo 84.- Suspensión de la prescripción de la acción

Si el comienzo o la continuación del proceso penal depende de cualquier cuestión que deba resolverse en otro procedimiento, se considera en suspenso la prescripción hasta que aquel quede concluido." 
prescripción como un medio de defensa en un procedimiento administrativo. Consideramos que ello solo será necesario en caso la autoridad no se haya percatado del paso del tiempo e incorrectamente inicie un procedimiento administrativo sancionador.

La redacción de la norma nacional es muy clara: "la facultad de la autoridad para determinar la existencia de infracciones administrativas prescribe en el plazo que establezcan las leyes especiales (...)". Vale decir, transcurrido el plazo, la autoridad pierde competencia y por lo tanto cualquier actuación en contrario sería violatoria del principio de legalidad que rige la actuación de la Administración Pública.

La confusión tiene su origen en el texto original de la LPAG, en el que, pese a establecer en la parte inicial de su primigenio artículo 233.1 exactamente lo mismo que el fraseo recogido en el párrafo precedente, dos párrafos después, en su artículo 233.3, indicaba que: "Los administrados plantean la prescripción por vía de defensa (...)", mostrando que la herencia civilista, a la que nos referimos precedentemente, aún está presente.

No ha sido sino hasta la promulgación del Decreto Legislativo 1272, a finales del 2016, que se aclaró legislativamente que la autoridad administrativa debe declarar de oficio la prescripción, en caso se percate de ello. ${ }^{3}$ Aunque pese a ser meridianamente claro - y que por ello no debería ser necesario- teniendo en cuenta la idiosincrasia jurídica de nuestro país y los antecedentes de discusión y debates estériles, hu- biese sido ideal que también aclare que no es necesario iniciarlo cuando se ha verificado que el plazo ha prescrito.

Por ello no se debería dar inicio a un procedimiento sancionador cuando el plazo de prescripción ha vencido. Pero, si se hiciese, el único acto administrativo válido que pueda ser emitido es el de declarar prescrita la facultad de determinar la existencia de infracción. Cualquier resolución en otro sentido contendría un acto administrativo incurso en la causal de nulidad establecida en el numeral 2) del artículo $10^{4}$ de la LPAG, vale decir la de faltarle un requisito de validez imprescindible y no conservable, como es el de ser emitido por un órgano competente.

Un tema relacionado estrechamente es el de la determinación del momento a partir del cual se debe contar el plazo de prescripción. La LPAG contempla tres momentos distintos:

a) El caso de las infracciones instantáneas o infracciones instantáneas de efectos permanentes. Una infracción instantánea es aquella que se consuma en un momento determinado -o determinable-. Éstas pueden ser instantáneas puras, como por ejemplo pasarse la luz roja de un semáforo; o instantáneas de efectos permanentes, como el ejemplo de los vecinos que "privatizan" la caIle instalando rejas. En ambos casos el plazo prescriptorio comenzará a correr desde el día en que la infracción es cometida.

b) El caso de las infracciones continuadas. Una infracción continuada es aquella que

3. Artículo 233.3 de la LPAG (hoy 252.3 en el TUO aprobado mediante Decreto Supremo №04-2019-JUS) "La autoridad declara de oficio la prescripción y da por concluido el procedimiento cuando advierta que se ha cumplido el plazo para determinar la existencia de infracciones. Asimismo los administrados pueden plantear la prescripción por vía de defensa y la autoridad debe resolverla sin más trámite que la constatación de los plazos.

En caso se declare la prescripción, la autoridad podrá iniciar las acciones necesarias para determinar las causas y responsabilidades de la inacción administrativa, solo cuando se advierta que se hayan producido situaciones de negligencia."

4. Artículo 10 de la LPAG

"Son vicios de nulidad del acto administrativo, que causan su nulidad de pleno derecho, los siguientes:

(...)

2) El defecto o la omisión de alguno de sus requisitos de validez, salvo que se presente alguno de los supuestos de conservación del acto a que se refiere el artículo 14." 
está compuesta por múltiples acciones que tienen en común estar afectando el mismo bien jurídico protegido y trasgrediendo la misma norma, como por ejemplo en las concertaciones en contra de la libre competencia, en que las conductas son múltiples y se extienden en el tiempo. En estos casos, la prescripción se comenzará a contar desde el momento en que se realiza la última conducta constitutiva de infracción.

c) El caso de las infracciones permanentes. Son aquellas que se realizan continuamente en el tiempo. Hay un momento de inicio de la conducta infractora, pero ésta se mantiene, como por ejemplo en el caso de una empresa de transportes que opera sin el permiso de circulación correspondiente. A diferencia de las instantáneas de efectos permanentes, en este caso no es el efecto sino la propia conducta la que perdura. En este caso, el plazo prescriptorio comenzará a contarse desde el día en que cese la acción infractora.

\section{LA REGLA GENERAL DEL PLAZO DE PRES- CRIPCIÓN DE LA LPAG}

Uno de los temas que mayor debate jurídico ha generado es el de la regla existente con relación al plazo de prescripción. Así algunos han afirmado, de manera errada, sobre todo en el plano de la defensa profesional, que la LPAG establece un plazo general de prescripción de cuatro años.

Ello no es correcto desde que el texto expreso de la norma establece que: "La facultad de la autoridad para determinar la existencia de infracciones administrativas, prescribe en el plazo que establezcan las leyes especiales (...). En caso ello no hubiera sido determinado, dicha facultad de la autoridad prescribirá a los cuatro (4) años."

Como se puede apreciar, la regla es que la prescripción opere "en el plazo que establezcan las leyes especiales". Vale decir, nuestro ordenamiento legal ha optado por atender a la especialidad de la infracción concreta, el plazo de prescrip- ción, pudiendo ser distinto caso por caso. Sólo en caso las leyes especiales no hayan previsto nada concreto sobre el plazo prescriptorio, éste se fija, por defecto, en cuatro años.

Ello tiene mucho sentido si es que se tiene en cuenta la gran cantidad de infracciones de distinta naturaleza y efectos que se pueden cometer desde el ámbito administrativo, así como el tiempo razonable que le pueda tomar a la Administración el detectarlo. No es lo mismo investigar un caso complejo como las prácticas restrictivas de la libre competencia - que prescribe en cinco años-, que un caso sencillo de infracción a los derechos de propiedad intelectual -que prescribe en dos años-, por ejemplo.

Por ello, con sabiduría la ley no ha querido establecer un plazo fijo de prescripción, sino uno variable en función de la complejidad que demande la investigación de cada caso en particular.

Se ha afirmado que el plazo de cuatro años, que como hemos explicado es uno "por defecto", sería en realidad una garantía mínima establecida en favor del administrado. Ello es incorrecto. Quienes sustentan esta posición se fundamentan en el artículo II del Título Preliminar y en el artículo 229 original, hoy 247 del TUO aprobado por Decreto Supremo № 004-2019-JUS.

El artículo II establece que: “(...) Las leyes que crean y regulan los procedimientos especiales no podrán imponer condiciones menos favorables a los administrados que las previstas en la presente Ley. (...)"; en tanto que la versión actual del 229 establece que:

“(...) Las disposiciones establecidas en el presente Capítulo se aplican con carácter supletorio a todos los procedimientos establecidos en leyes especiales, incluyendo los tributarios, los que deben observar necesariamente los principios de la potestad sancionadora administrativa a que se refiere el artículo 248, así como la estructura y garantías previstas para el procedimiento administrativo sancionador. Los procedimientos especiales no pue- 
den imponer condiciones menos favorables a los administrados, que las previstas en este capítulo. (...)"

Son tres categorías jurídicas las involucradas en estos artículos: principios de la potestad sancionadora; garantías previstas para el procedimiento sancionador; $y$, condiciones menos favorables a los administrados que las establecidas en la ley - en general- y en el capítulo del procedimiento sancionador —en particular-.

De ellos, el único que aparece con claridad en el texto de la LPAG es el de los principios de la potestad sancionadora del Estado, contemplados y definidos como tales de manera expresa en el artículo 230 del texto original y hoy en el artículo 248 del TUO. Sin embargo, las "garantías" $y$ las "condiciones" son dejadas a la interpretación.

En ese sentido se debe explorar si el plazo prescriptorio de cuatro años constituye una garantía o una condición mínima del administrado ante el ejercicio de la potestad sancionadora del Estado.

Considero que se debe distinguir entre la prescripción, propiamente dicha, y el plazo establecido para que ésta opere. Así, mientras la prescripción en sí misma si constituye una garantía para el administrado, como una suerte de "seguro" contra la lentitud de la administración pública y una eventual "espada de Damocles" blandiendo permanentemente sobre su cabeza; el plazo sólo lo es en cuanto a la característica de que debe ser "razonable".

Cuando la norma establece la prescripción de la competencia de la Administración Pública para determinar una infracción, lo que está haciendo es establecer que en toda situación de ejercicio de la potestad sancionadora, ésta no se puede ejercer de manera indeterminada en el tiempo, sino que debe estar sujeta a un plazo prescriptorio. Tan evidente es esta garantía, que la misma norma establece que en caso no exista alguna norma especial que establezca la prescripción, el plazo por defecto será de 4 años.

De esta manera la LPAG se asegura que aún en el caso que una ley especial que regule un procedimiento administrativo sancionador no haya previsto la existencia de un plazo de prescripción, éste siempre va a existir y va a ser determinado en cuatro años. Pero de ninguna manera está estableciendo que ese plazo, establecido por defecto, tenga que ser como máxi-ADMINISTRATIVo mo de esa cantidad de años.

Es por ello que afirmamos que la existencia de la prescripción de la potestad sancionadora del Estado constituye una garantía establecida en favor del ciudadano, por lo que no se podría, por ejemplo, aprobar una norma que contemple un procedimiento sancionador en el que se establezca la imprescriptibilidad de dicha potestad en algún caso concreto.

La extensión del plazo es un tema diferente. Aquí no estamos ante una garantía del administrado, sino del desarrollo del principio de razonabilidad aplicado a una garantía - la existencia misma de la prescripción-. Cada caso es diferente y no resulta razonable aplicar un plazo estándar para aquello que no lo es. La variedad de temas sujetos a la potestad sancionadora del Estado es tal que la LPAG con sabiduría decidió dejar a la legislación especial la tarea de definir los plazos adecuados para cada tema en particular. Uno, dos, tres o más años deberán ser definidos en función del tipo de infracción particular y su dificultad en descubrirlo y procesarlo. Y para dejarlo en claro, lo estableció con una redacción que deja poco espacio a la duda: "la facultad de la Autoridad (...) prescribe en el plazo que establezcan las leyes especiales".

¿El plazo de prescripción de una ley especial puede ser superior a los cuatro años establecidos por defecto en la LPAG? Pues claro que sí. Nada impide establecer plazos superiores o inferiores a ese plazo que es de aplicación supletoria ante la falta de una definición específica en la legislación especial. No debemos confundir un plazo supletorio que sí constituye una garantía, pero no de plazo, sino de la existencia misma de un plazo de prescripción razonable en todo procedimiento administrativo, aún cuando ello no haya sido previsto expresamente por la legislación especial que lo regule.

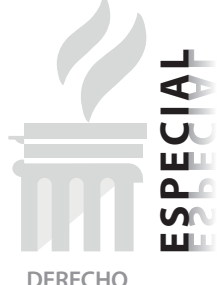
O 
Por otro lado, considero que el plazo por defecto de 4 años resulta excesivo y solo es explicable en querer justificar o apañar a una administración pública lenta e ineficiente, incapaz de manejar sus potestades en tiempo y forma oportuna. Hay que recordar que, en la defensa de intereses jurídicos mayores, la legislación penal ha establecido como plazo de prescripción para las faltas un año. ${ }^{5}$

La lentitud de la Administración Pública en perseguir las infracciones administrativas también se puede explicar en el afán persecutorio y sancionador que se ha puesto de moda en nuestra sociedad en la que se busca inventar infracciones por cualquier cosa y en donde las entidades del Sistema Nacional de Control, por ejemplo, confunden fácilmente errores administrativos con actos de corrupción.

La desesperada búsqueda por parte de una Administración desprestigiada, del favor de la opinión pública, ha generado incentivos muy fuertes para encontrar -o inventar- infracciones por doquier, de modo tal que a la par que se justifica el trabajo, se sacia la necesidad social de sentir que se está haciendo algo en contra de las conductas indebidas de los ciudadanos y funcionarios que no respetan la ley. Entonces, hay un exceso de trabajo en el ejercicio de la potestad sancionadora que la administración, con los recursos y personal que cuenta, no puede atender rápidamente.

Desde mi perspectiva se debería evaluar la razonabilidad de mantener un plazo tan extenso de prescripción por defecto de regulación específica. Considero que debiera optarse por un plazo flat de dos años o uno escalonado en función de la gravedad del bien jurídico protegido por la legislación particular.
Sin embargo, debe quedar bien claro que este es un plazo supletorio de la existencia de uno establecido en una ley especial.

\section{EN CONCLUSIÓN}

a) La existencia de un plazo de prescripción de la potestad sancionadora del Estado es una de las garantías del debido procedimiento establecida en favor del administrado. La extensión del plazo no lo es.

b) Los plazos establecidos para el ejercicio de la facultad de la administración de determinar la existencia de infracciones no se interrumpen, solo se suspenden en caso la autoridad haya notificado la comunicación de cargos al investigado.

c) El transcurso del plazo prescriptorio elimina la competencia de la autoridad administrativa para sancionar. Por ello es incorrecto iniciar un procedimiento administrativo sancionador cuando la prescripción ha operado. En caso no se percate de ello e indebidamente lo inicie, al notarlo de oficio o que el administrado plantee la prescripción en vía de defensa, deberá proceder a emitir un acto administrativo dando por concluido el procedimiento.

d) El plazo para el ejercicio de la facultad de la administración para determinar la existencia de infracciones es, como regla general, aquel que sea establecido en una ley especial, atendiendo a las particularidades de la materia y la complejidad que ella pueda tener. Y sólo, en caso ello no haya sido contemplado en una ley especial, el plazo supletorio será de 4 años.

5. Artículo 440 del Código Penal aprobado por Decreto Legislativo 635

"Artículo 440.- Disposiciones comunes

Son aplicables a las faltas las disposiciones contenidas en el Libro Primero, con las modificaciones siguientes:

(...)

5. La acción penal y la pena prescriben al año. En caso de reincidencia y habitualidad, prescriben a los dos años. Las faltas previstas en los artículos 441 y 444 prescriben a los tres años, salvo en los supuestos de reincidencia o habitualidad, en cuyo caso es de aplicación el artículo 80." 